\title{
Amino acid restriction alters survival mechanisms in pancreatic beta cells: possible role of the PI3K/Akt pathway
}

\author{
Bruna Lourençoni Alves ${ }^{1}\left[\right.$. Thiago dos Reis Araújo ${ }^{1}$. Dimitrius Santiago Passos Simões Fróes Guimarães ${ }^{1}$. \\ Cláudio Cesar Zoppi ${ }^{1} \cdot$ Mariana Sarto Figueiredo $^{2} \cdot$ Everardo Magalhães Carneiro $^{1}$
}

Received: 5 October 2020 / Accepted: 16 April 2021 / Published online: 28 April 2021

○) Springer-Verlag GmbH Germany, part of Springer Nature 2021

\begin{abstract}
Background and aims Malnutrition in the early stages of life may lead to changes in the glycemic metabolism during adulthood, such as pancreatic beta cells dysfunction and failure. Therefore, this study aimed to evaluate the effects of an in vitro amino acid restriction model on the function and viability of pancreatic beta cells.

Methods Insulin-producing cells (INS-1E) were maintained in control or amino acid restricted culture medium containing $1 \times$ or $0.25 \times$ of amino acids, respectively, for $48 \mathrm{~h}$.

Results Amino acid restricted group showed lower insulin secretion and insulin gene expression, reduced mitochondrial oxygen consumption rate and reactive oxygen species production. Besides, amino acid restricted group also showed higher levels of endoplasmic reticulum stress and apoptosis markers and enhanced Akt phosphorylation. However, even with higher levels of apoptosis markers, amino acid restricted group did not show higher levels of cell death unless the PI3K/Akt pathway was inhibited.
\end{abstract}

Conclusion Amino acid restricted beta cell viability seems to be dependent on the PI3K/Akt pathway.

Keywords Insulin secretion $\cdot$ Redox balance $\cdot$ Heat shock protein $\cdot$ Apoptosis $\cdot$ Cell viability

\section{Introduction}

Adequate nutrition is crucial for healthy growth and development during childhood. Malnutrition remains one of the most important causes of morbidity and mortality among children in the world, being responsible for around $45 \%$ of deaths among children under 5 years old [1,2]. Malnutrition, whether intrauterine or postnatal, is considered a risk factor for the development of metabolic pathologies in adult life, such as obesity, type 2 Diabetes Mellitus, hypertension, coronary artery disease, dyslipidemia, among others [3-6], and it is a world health issue affecting mainly children. Besides,

Everardo Magalhães Carneiro

emc@unicamp.br

1 Obesity and Comorbidities Research Center (OCRC), Department of Structural and Functional Biology, Institute of Biology, University of Campinas (UNICAMP), R Carl Von Linnaeus, Campinas, SP CEP 13083-865, Brazil

2 Department of Nutrition and Dietetic, Faculty of Nutrition, Federal Fluminense University, Niteroi, RJ, Brazil this situation can be aggravated by increasing global poverty risk due to the COVID-19 pandemic [7, 8].

Experimental studies showed that protein restriction during pregnancy, lactation, or after weaning impacts the development of the endocrine pancreas, reducing insulin synthesis and secretion when stimulated by glucose, amino acids, and other enhancers [9-12]. The reduction in pancreatic beta cell responsiveness to secretagogues, in case of protein restriction, is probably associated with lower expression of key proteins of the stimulus-coupling mechanisms [10, 13, 14], establishing a direct relationship among the restriction of nutrients in the initial phase of life and its consequences to the endocrine pancreas function.

Besides the dysfunction in amino acid restricted beta cells, amino acid restriction-induced alterations have also been shown in an in vitro model of malnutrition. Our group reported that these cells were more susceptible to death when exposed to a nutrient challenge [15]. However, the intracellular mechanisms involved with this outcome are still unknown.

Previous studies reported changes in antioxidant enzymes activity and reactive oxygen species concentration in islets 
from protein malnourished rodents $[16,17]$. However, studies investigating the effects of amino acid restriction on beta cell viability are still scarce. Here, we hypothesized that beta cells submitted to an amino acid restriction could be more susceptible to death due to higher oxidative damage. We aimed to analyze the effects of in vitro amino acid restriction on mitochondrial metabolism, redox status, and apoptosis markers in an insulin-producing cell line (INS-1E), as well as the molecular mechanisms involved in these responses.

\section{Materials and methods}

\section{Cell culture}

INS-1E cells (RRID: CVCL_0351) were cultured in RPMI 1640 medium (10-040CV, Corning) containing sodium bicarbonate and glutamine, supplemented with 5\% fetal bovine serum (FBS), 10-mM HEPES, 1-mM sodium pyruvate, $50-\mu \mathrm{M} \beta$-mercaptoethanol, 100-U/ml penicillin, 100$\mathrm{mg} / \mathrm{ml}$ streptomycin and kept in an incubator (CO-24, New Brunswick Scientific Co., Inc., New Jersey, USA) at $37^{\circ} \mathrm{C}$, in a humidified atmosphere at $5 \% \mathrm{CO}_{2}$. Cells were passaged once a week and each passage were considered as a different $n$. Biological replicates are not considered as different n. For amino acid restriction protocol, cells were cultured for $48 \mathrm{~h}$ in an amino acid-free medium (D1824, Vitrocell) and supplemented with $1 \times($ Control $-\mathrm{C}$ ) or $0.25 \times$ (Amino acid Restriction-R) of an amino acid solution (RPMI 1640 Amino Acids Solution-50X, R7131, Sigma-Aldrich), as previously established by Gonçalves et al. (2019). INS1-E were kindly provided by Dr. Decio Eizirik, ULB, Brussels, Belgium.

\section{Static insulin secretion}

INS-1E cells were grown in 24-well plates and after amino acids restriction, they were pre-incubated with Krebs buffer (115-mM NaCl, 5-mM KCl, 2.56- $\mathrm{mM} \mathrm{CaCl}_{2}, 1-\mathrm{mM} \mathrm{MgCl}_{2}$, $10 \mathrm{mM} \mathrm{NaHCO} 3,15-\mathrm{mM}$ HEPES, and $0.3 \%$ glucose-free bovine serum albumin (BSA) and balanced with a mixture of $95 \% \mathrm{O}_{2} / 5 \% \mathrm{CO}_{2}$ to a $\mathrm{pH}$ of 7.4 ), at $37{ }^{\circ} \mathrm{C}$, for $1 \mathrm{~h}$. Subsequently, the solution was gently removed and replaced with $500 \mu \mathrm{L}$ of the same solution (Krebs) containing different concentrations of glucose ( 2.8 and $22.2 \mathrm{mM}$ ) for $1 \mathrm{~h}$. The supernatant was removed, transferred to test tubes, and stored at $-20^{\circ} \mathrm{C}$ for subsequent analysis of insulin by radioimmunoassay [18]. The cells were collected using urea/thiourea buffer for later protein measurement [19] and normalization of the results by dividing the insulin concentration by protein content.

\section{Western blot analyses}

After treatment, INS-1E cells were washed in PBS (Phosphate Buffered Saline) $1 \mathrm{X}$ and then collected in lysis buffer containing protease inhibitors. A small sample was used for protein quantification by Bradford (BioRad), using a standard curve of known concentrations as a reference. $20 \%$ of the volume of Laemmli $5 \mathrm{X}$ buffer $(0.1 \%$ bromophenol blue, 1-M sodium phosphate, $50 \%$ glycerol, $10 \%$ SDS) was added and then they were incubated at $100{ }^{\circ} \mathrm{C}$ for $5 \mathrm{~min}$. The proteins were separated by sodium dodecyl sulfate-polyacrylamide gel electrophoresis and blotted to a nitrocellulose membrane with a $0.22-\mu \mathrm{m}$ pore (BioRad). The membranes were blocked with 5\% albumin in TBS-T solution (50-mM Tris $\mathrm{pH} 7.5,150-\mathrm{mM} \mathrm{NaCl}$, and $0.1 \%$ Tween 20) for $90 \mathrm{~min}$ at room temperature, and the proteins related to the study were detected on the membrane by overnight incubation with specific antibody for the proteins of interest (Supplementary Table 1). Then, the membrane was washed with TBS-T and incubated with peroxidase-conjugated polyclonal anti-IgG antibody (dilution 1:10,000 in TBS-T with 3\% albumin) for 90 min. Right after, the membranes were washed again and, finally, were imaged by chemiluminescence (SuperSignal West Femto, Pierce Biotechnology Inc., Rockford, IL, USA) through Amersham Imager 600 (GE Healthcare, Little Chalfont, UK). Optical density was quantified using ImageQuant TL v8.1 software (GE Healthcare Life Sciences).

\section{Real-time PCR analyses}

After treatment, INS-1E cells were lysed in $500 \mu \mathrm{l}$ of Trizol solution (Ambion by Life Technologies, USA), and total RNA was extracted according to the manufacturer's protocol. RNA concentrations were determined by spectrophotometry (ratio 260/280 nm). The cDNA was synthesized with $1 \mu \mathrm{g}$ of RNA, using reverse transcriptase reaction (High-Capacity cDNA Reverse Transcription kit, Applied Biosystems, USA). Real-time PCR was performed using Fast SYBR ${ }^{\circledR}$ Green PCR Master Mix (Applied Biosystems, USA) in a 7500 Fast Real-Time PCR System (Applied Biosystems) thermocycler with specific primers for the PCR reactions (Supplementary Table 2). Gene expression was quantified according to the $\Delta \Delta \mathrm{CT}$ method [20] using HPRT gene as the constitutive gene.

\section{Mitochondrial density and mitochondrial membrane potential}

After $48 \mathrm{~h}$ of treatment, the cells were incubated with a fluorescent Mitotracker probe (M7514, Invitrogen) at $100 \mathrm{nM}$ (diluted in Krebs 11.1-mM glucose) for $15 \mathrm{~min}$ at $37^{\circ} \mathrm{C}$ to 
assess mitochondrial density or with Tetramethylrhodamine methyl ester perchlorate (TMRM-T5428, Sigma-Aldrich) at $30 \mathrm{nM}$ (diluted in Krebs 11.1-mM glucose) for $30 \mathrm{~min}$ at $37{ }^{\circ} \mathrm{C}$ to evaluate the cell membrane potential. The cells were then washed three times with PBS and the fluorescence reading was performed in the Spectramax M3 fluorimeter plate reader (Molecular Devices), at 490-nm (excitation) and 516-nm (emission) wavelengths for Mitotracker and at 545-nm (excitation) and 575-nm (emission) wavelengths for TMRM. For results normalization, cells were washed with PBS, fixed with $4 \%$ formaldehyde for $10 \mathrm{~min}$, washed again with PBS, then stained with Hoechst 33,342 (ThermoFisher, $\mathrm{H} 3570 ; 10 \mathrm{mg} / \mathrm{mL}$ ) at a final concentration of $1 \mu \mathrm{g} / \mathrm{mL}$ for 15 min, washed again with PBS and then read on this same equipment at 350-nm (excitation) and 461-nm (emission) wavelengths.

\section{Mitochondrial respiration by high-resolution respirometry}

The oxygen consumption rates (OCR) were measured in an Oxygraph-2 k (OROBOROS Instruments, Innsbruck, Austria) using 1.5 million cells/group in culture media. To evaluate the contribution of each respiratory complex to the OCR, the following drugs were added: $1-\mu \mathrm{M}$ oligomycin to inhibit ATP synthase; sequential $0.5 \mu \mathrm{M}$ additions of the uncoupler carbonyl cyanide-4-trifluoromethoxy phenylhydrazone (FCCP) until maximum respiration consumption was achieved; $2 \mu \mathrm{M}$ of antimycin to inhibit complex III and block mitochondrial respiration. ATP-linked OCR (ATPlinked) was calculated by subtracting consumption after the addition of oligomycin from baseline respiration. The spare capacity was determined by subtracting the baseline consumption from maximal respiration (induced by the FCCP). The proton-leak was calculated by subtracting the non-mitochondrial consumption of OCR after oligomycin. Maximum and baseline consumption were obtained by subtracting the respiration after titration of FCCP and initial (baseline) respiration of non-mitochondrial OCR. The values of the bar and line graph are composed of the absolute values obtained in the experiment $(n=3)$.

\section{Production of reactive oxygen species (ROS)}

After $48 \mathrm{~h}$ of treatment, cells were subjected to a protocol similar to that of insulin secretion, in which they were incubated for $1 \mathrm{~h}$ in Krebs buffer without glucose and later stimulated with that same solution with $22.2-\mathrm{mM}$ glucose for $1 \mathrm{~h}$. During the last $30 \mathrm{~min}$, probes were added to assess the ROS levels. The generation of mitochondrial and cytosolic superoxide radicals was quantified using MitoSOX ${ }^{\mathrm{TM}}$ Red Mitochondrial Superoxide Indicator (M36008, ThermoFisher) and Dihydroethidium (Hydroethidine) (D11347,
ThermoFisher), respectively. For total $\mathrm{H}_{2} \mathrm{O}_{2}$ quantification, the Amplex ${ }^{\mathrm{TM}}$ UltraRed Reagent probe (A36006, ThermoFisher) was used. Fluorescence was measured using a fluorescent plate reader (Spectramax M3 fluorimeter, Molecular Devices) according to the manufacturer's recommendations. The values obtained were normalized by the amount of protein (Bradford) or the number of cells (stained with Hoechst 33342).

\section{PI3K/Akt pathway inhibition}

The cells were treated or not with a pharmacological and irreversible inhibitor of PI3K (Wortmannin, W1628, SigmaAldrich) for $30 \mathrm{~min}$ before the $48 \mathrm{~h}$ of treatment with amino acid restriction. Initially, different concentrations of this compound (100 nM, $500 \mathrm{nM}, 1 \mu \mathrm{M}, 5 \mu \mathrm{M}$, and $10 \mu \mathrm{M})$ were tested, and cells were collected for analysis of protein content by western blot. With the lowest tested concentration chosen, experiments were then carried out to evaluate cell death and the production of ROS (DHE) and $\mathrm{H}_{2} \mathrm{O}_{2}$ (Amplex).

\section{Cell death}

Cell viability was assessed from cells stained with DNA intercalants, Hoechst 33,342 (ThermoFisher, H3570; 10 mg/ $\mathrm{mL}$ ), and propidium iodide (ThermoFisher, P3566; $10 \mathrm{mg} /$ $\mathrm{mL})$. For the experiment, cells were cultured in a 96-well plate $\left(\mu \mathrm{CLEAR}^{\circledR}\right.$, Greiner) and after $48 \mathrm{~h}$ of treatment, $100 \mu \mathrm{L}$ of the medium was removed from each well and 100 $\mu \mathrm{L}$ of RPMI 1640 medium containing both substances were added (reagents mentioned above were in the final concentration of $10 \mu \mathrm{g} / \mathrm{mL}$ ). After $15 \mathrm{~min}$ of incubation at $37^{\circ} \mathrm{C}$, $100 \mu \mathrm{L}$ of the medium was removed from each well and $100 \mu \mathrm{L}$ of RPMI 1640 medium was added. The percentage of apoptotic cells was determined by the High Content Imaging System (ImageXpress, Molecular Devices) using the Live and Dead module of the MetaXpress software (Molecular Devices). To identify viable and dead populations, masks were applied for DAPI wavelengths (excitation at $350 \mathrm{~nm}$ and emission at $470 \mathrm{~nm}-$ Hoescht) and Texas red (excitation at $496 \mathrm{~nm}$ and emission at $615 \mathrm{~nm}$-propidium iodide).

\section{Statistical analysis}

Statistical analyses were performed using the GraphPad Prism 7.0 software (GraphPad Software, USA). The results were expressed as mean \pm standard error of the mean (SEM) and all were submitted to the Shapiro-Wilk normality distribution test and then directed to parametric (Student's $t$ test) or nonparametric (Mann-Whitney $U$ test). For the experiments that used Wortmannin, the results 
(a)

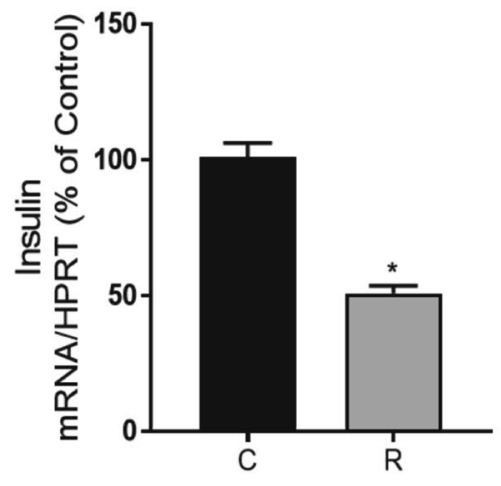

(c)

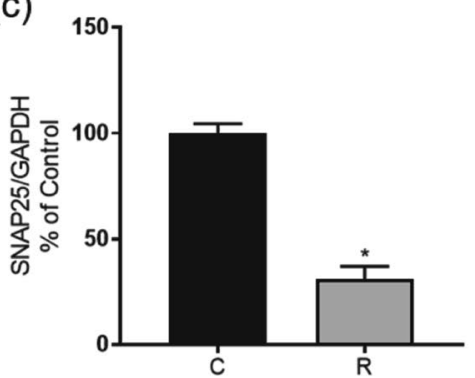

(f)

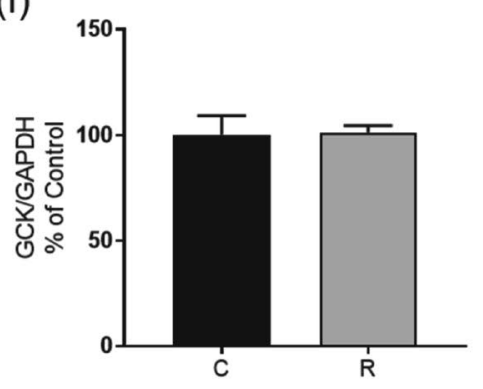

(b)

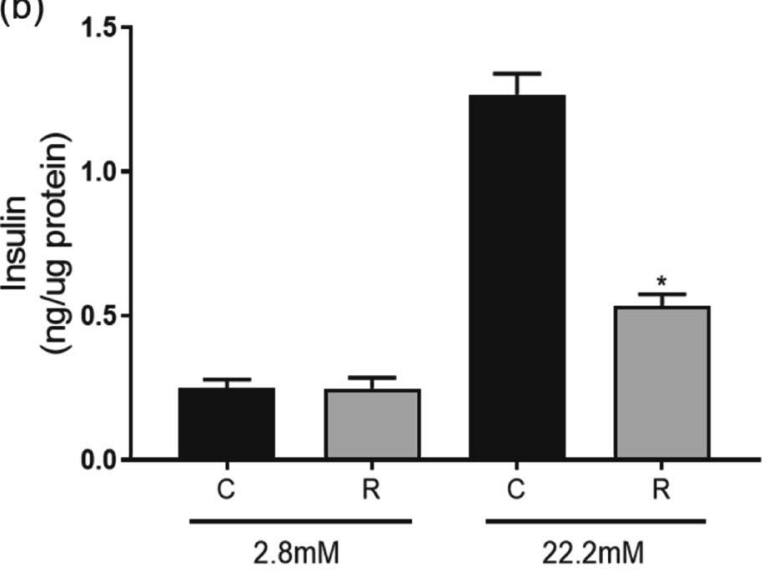

(d)

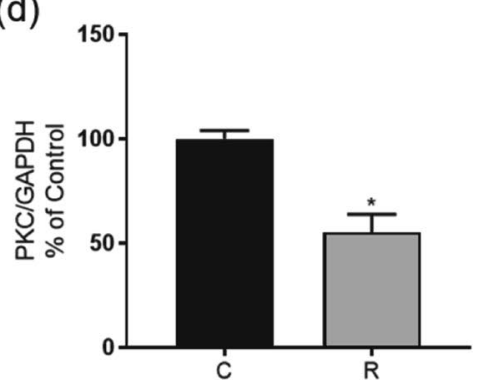

(e)

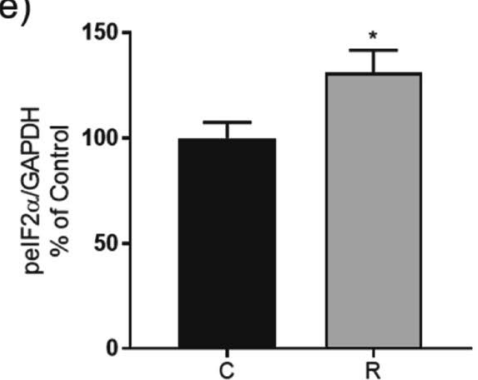

$\begin{array}{lllllllllllllll}C & R & C & R & C & R & C & R\end{array}$

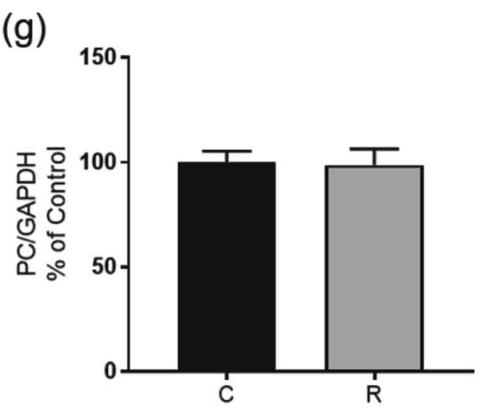

(h)

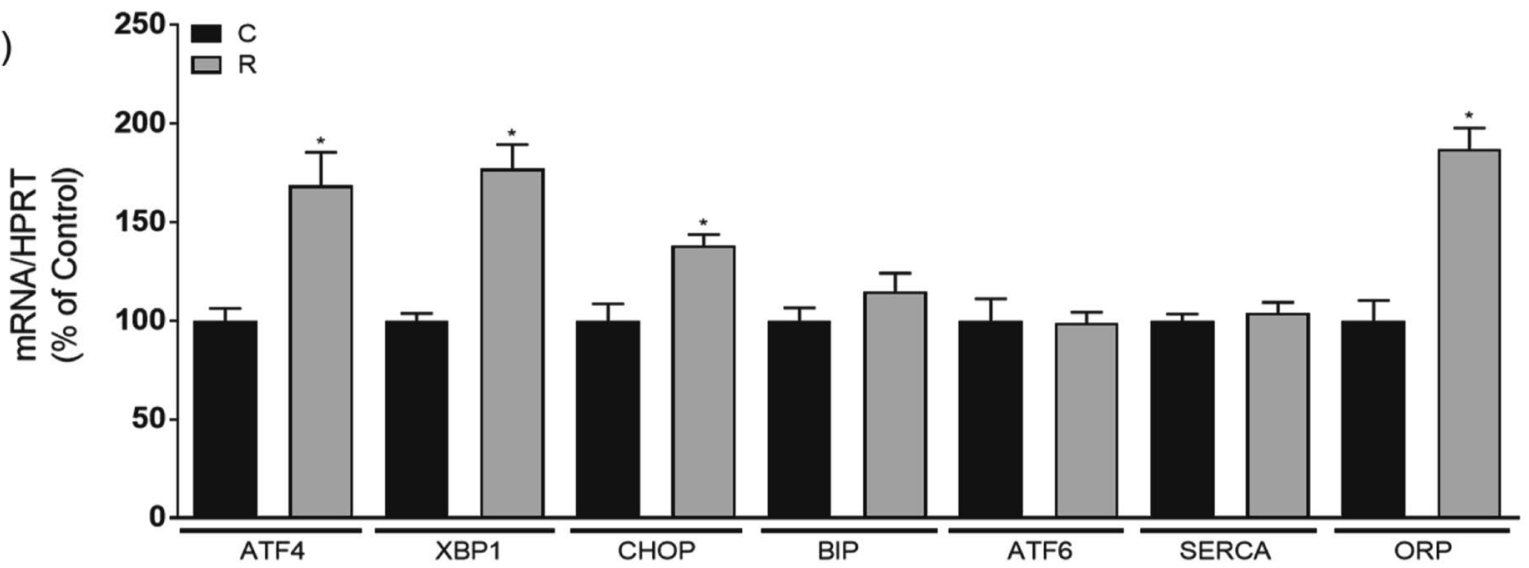


4Fig. 1 Characterization of in vitro amino acid restriction model in insulin-producing cells (INS-1E) after $48 \mathrm{~h}$ cultured with $1 \times(\mathrm{C})$ or $0.25 \times(\mathrm{R})$ of amino acids. a Insulin gene expression $(\mathrm{n}=7)$. b Static insulin secretion stimulated by 2.8 and $22.2 \mathrm{mM}$ of glucose $(n=8)$. cg Protein content of SNAP-25, p-eIF2 $\alpha$, PKC, PC and GCK. h Gene expression of endoplasmic reticulum markers $(n=5-8$ for Western Blot and PCR). c-g Normalized by GAPDH and expressed in $\%$ of Control. $* R$ is different from $C$. Data are mean \pm SEM and were submitted to Student $t$ test for all analyses, $p<0.05$

were analyzed by Two-way ANOVA, followed by Bonferroni. $p<0.05$ was adopted as a significance criterion.

\section{Results}

\section{Characterization of the in vitro amino acid restriction model}

Initially, we reproduced the phenotype found in animal malnutrition models in vitro, using INS-1E cells. We treated cells with amino acids restricted $(\mathrm{R})$ and control (C) medium. Amino acid restriction reduced insulin gene expression by $50 \%$ and insulin secretion stimulated by glucose by $58 \%$ (Fig. 1a, b, respectively). Amino acid restriction in vitro led to a reduction of $70 \%$ in SNAP-25 protein content (Fig. 1c) and 45\% of protein kinase C (PKC, Fig. d), and an increase of $30 \%$ in phospho-eukaryotic translation initiation factor $2 \alpha$ (p-eIF2 $\alpha$, Fig. 1e). The protein content of pyruvate carboxylase (PC, Fig. 1f) and glucokinase (GCK, Fig. 1g) did not change. It was reported an increase in gene expression of activating transcription factor 4 (ATF4) by 68\%, X-box-binding protein 1 (XBP1) by $77 \%, \mathrm{C} / \mathrm{EBP}$ homologous protein (CHOP) by $38 \%$ and oxygen-regulated protein 150 (ORP) by $87 \%$ (Fig. 1h).

\section{Mitochondrial metabolism}

Despite no changes in the protein content of peroxisome proliferator-activated receptor-gamma coactivator 1-alpha (PGC1 $\alpha$, Fig. 2a), amino acid restriction reduced the mitochondrial density by $37 \%$ (Fig. 2b) and mitochondrial membrane potential by $29 \%$ (Fig. 2c). Accordingly, we reported a reduction in the protein content of complex I by $42 \%$ and in complex IV by $58 \%$ (Fig. 2 d). As shown in Fig. 2e, f, cells that have undergone amino acid restriction already started with lower baseline $\mathrm{O}_{2}$ consumption. Also, the respiratory parameters proton-leak, maximal respiration, and spare respiratory capacity were reduced in the restricted group by $33 \%, 37 \%$, and $45 \%$, respectively.

\section{Cell viability and evaluation of parameters related to oxidative stress and apoptosis}

We evaluated the production of $\mathrm{H}_{2} \mathrm{O}_{2}$ (Fig. 3a) and the production of total mitochondrial and cytosolic reactive oxygen species, which are shown in Figs. 3b, c, respectively. Surprisingly, we observed that $\mathrm{H}_{2} \mathrm{O}_{2}$ and cytosolic reactive oxygen species (ROS) content were reduced in the amino acid restricted group by about $30 \%$ in both experiments, while mitochondrial ROS showed no difference between groups. We also reported an increase in superoxide dismutase 1 (SOD1, Fig. 3d) and superoxide dismutase 2 (SOD2, Fig. 3e) protein content by 32 and $36 \%$, respectively, in this group. Considering the changes found in the restricted group, we investigated whether cell viability would be altered. For that, we assessed some proteins involved with the intrinsic pathway of cell apoptosis and did not observe any difference in the protein content of Sirtuin 1 (SIRT1, Fig. 3f) and heat shock factor (HSF1, Fig. 3g) between groups. However, heat shock protein 70 (HSP70) protein content was shown to be decreased by $41 \%$ (Fig. $3 \mathrm{~h}$ ) and Bax/Bcl-xL ratio increased by $40 \%$ (Fig. 3i). Nevertheless, no difference in the number of apoptotic cells between groups (Fig. 3j) was reported.

While evaluating some of the major survival signaling pathways, we found that the amino acid restricted group displayed an eightfold increase in Akt phosphorylation (Fig. 4a). To investigate whether this increase was related to cell survival, we used Wortmannin to inhibit the PI3K/Akt pathway (Fig. 4b). This inhibition evidenced significantly higher rates of cell death (Fig. 4c-g; Fig. c-f is the representative images of HOPI experiment) and ROS production (Fig. 4h), despite no change in $\mathrm{H}_{2} \mathrm{O}_{2}$ content (Fig. 4i).

\section{Discussion}

To start this study, we first reproduced the in vitro model of amino acid restriction. As well as Gonçalves et al. (2019), we measured protein content of SNAP-25 and PKC, which reduction corroborated the findings reported in islets of rodents submitted to protein restriction [13, 21].

Moreover, p-eIF $2 \alpha$ protein content, ATF 4 and XBP1 gene expression were increased after $48 \mathrm{~h}$ of treatment with $0.25 \times$ of amino acids. Eukaryotic translation initiation factor $2 \alpha$ plays an important role in protein synthesis regulation, especially when amino acid availability is limited. It is an essential biomarker for amino acid restriction and an upstream protein of the PERK/ATF4 branch of unfolded protein response (UPR). UPR signaling is essential for beta cell maintenance, activating mechanisms involved with cell survival and death, according to cell stress situation [22].

We also observed increased CHOP and ORP150 gene expression. CHOP is a pro-apoptotic transcription factor, 
Fig. 2 Evaluation of mitochondrial metabolism in insulinproducing cells (INS-1E) after $48 \mathrm{~h}$ cultured with $1 \times(\mathrm{C})$ or $0.25 \times(\mathrm{R})$ of amino acids. a Protein content of PGC1 $\alpha$ $(n=4)$. b Mitochondrial density by fluorescent Mitotracker probe $(n=7)$. $\mathbf{c}$ Mitochondrial membrane potential by fluorescent TMRM probe $(n=7)$. (d) Protein content of OXPHOS $(n=5)$. e, f Mitochondrial activity through oxygen consumption represented in line graph and bars $(n=3)$. (a and d) Normalized by GAPDH and expressed in $\%$ of Control. $* R$ is different from C. Data are mean \pm SEM and were submitted to Student $\mathrm{t}$ test for all analyses, $p<0.05$

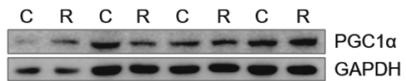

(a)

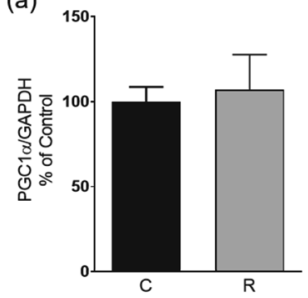

(b)

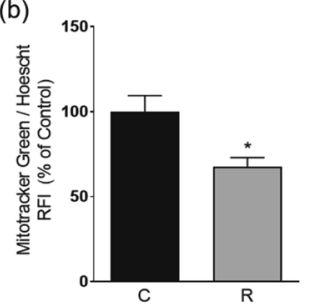

(c)

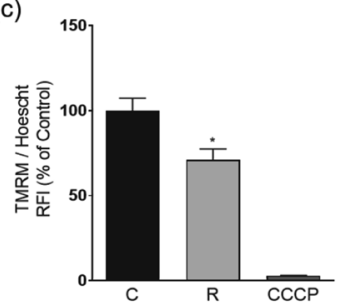

(d)

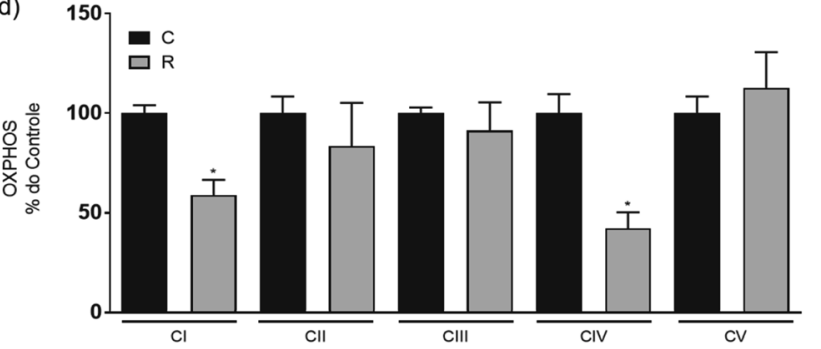

$\begin{array}{llllll}C & R & C & R & C & R\end{array}$
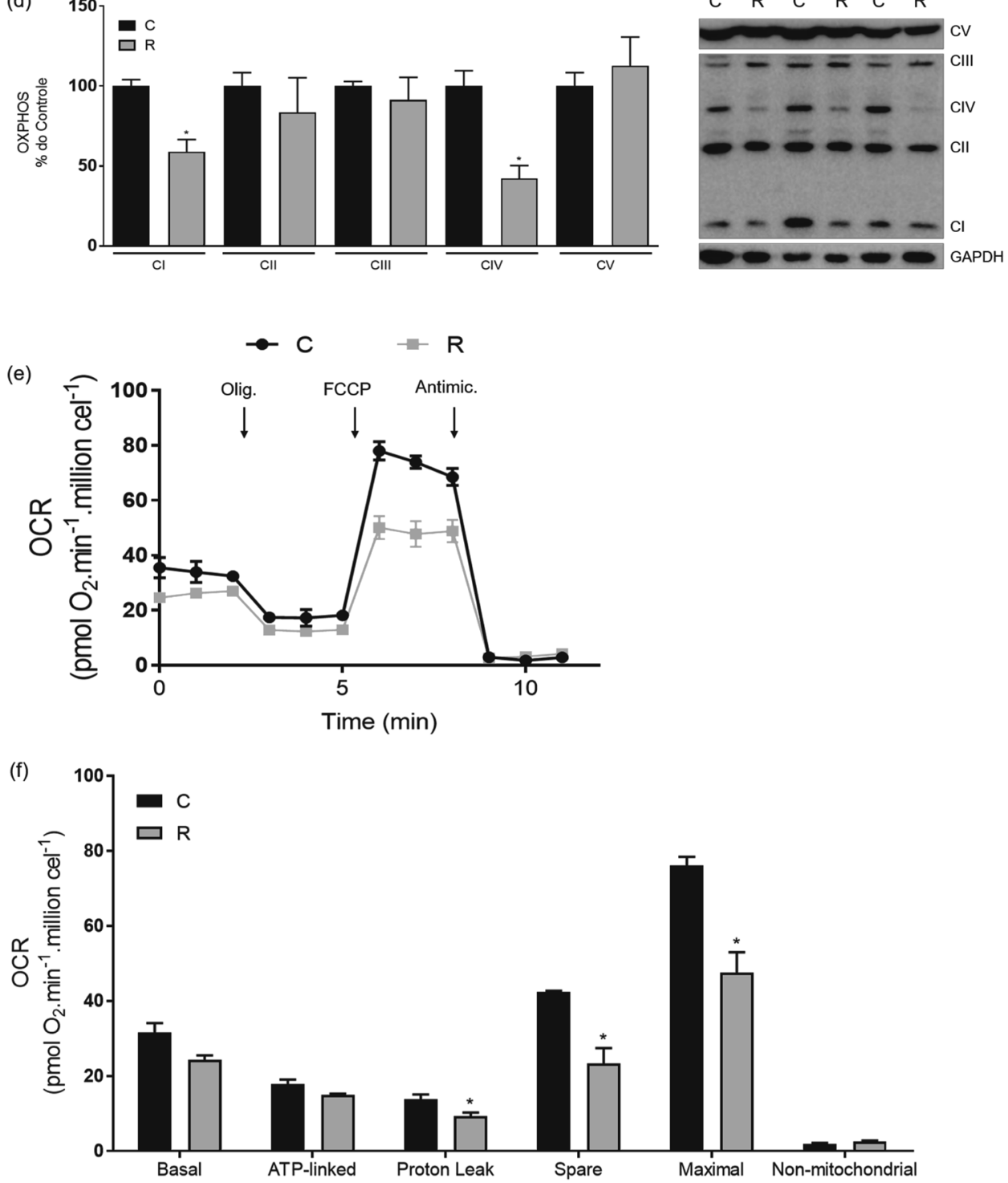

stimulated by PERK/ATF4 pathway, while ORP150 is an inducible ER chaperone that is up-regulated after cellular insults $[23,24]$. Although its exact mechanism of action still remains unclear, ORP150 is proposed to have a cytoprotective role for the maintenance of cellular viability [25-27]. CHOP/ORP150 ratio was proposed to be an important predictor for cell apoptosis triggering during ER stress in diabetic peripheral neuropathy [28]. Our results evidence that this ratio could also be a marker for beta cells, since ER stress markers are increased, but there is no cell death yet.

Mitochondrial dysfunction also triggers ER stress activation. In agreement with previous studies, our results show 
(a)

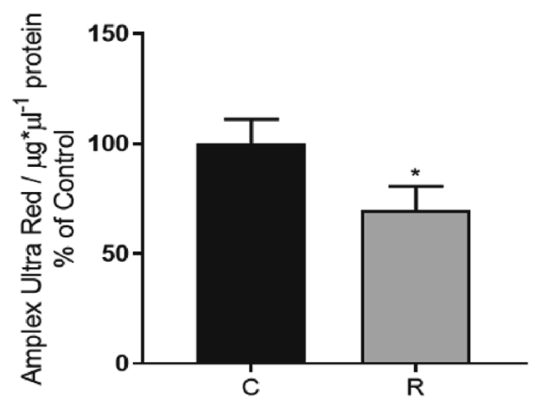

(d)

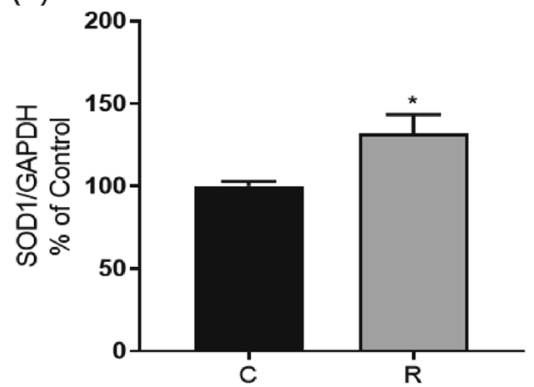

(g)

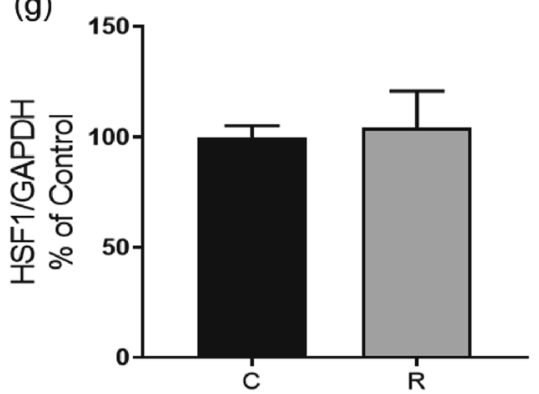

(j)

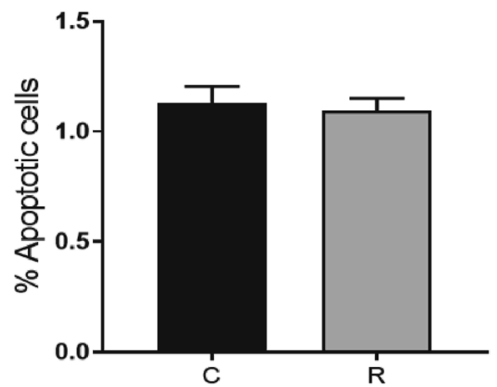

(b)

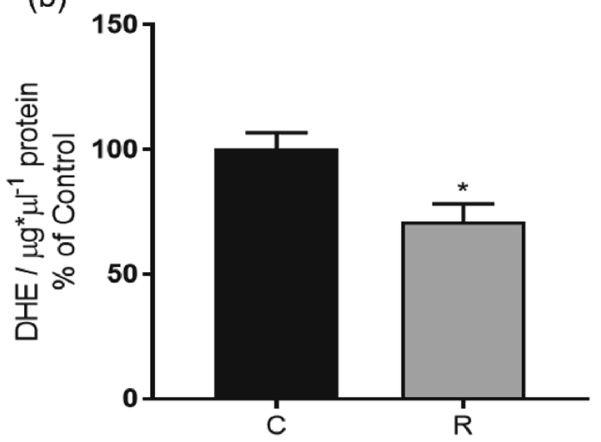

(e)

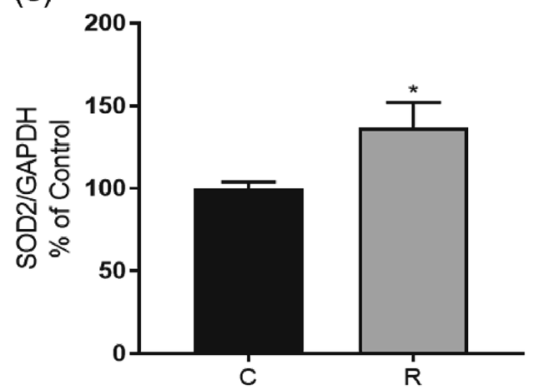

(h)

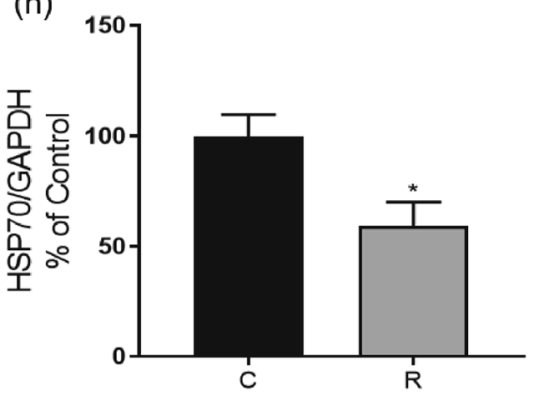

(c)

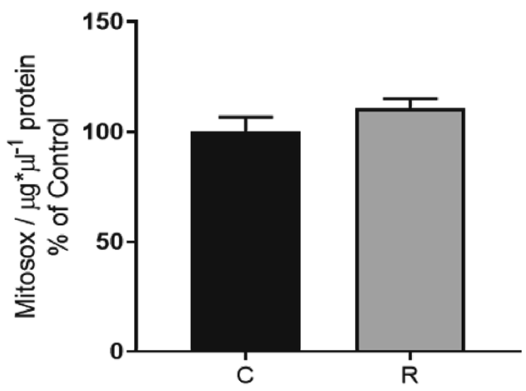

(f)
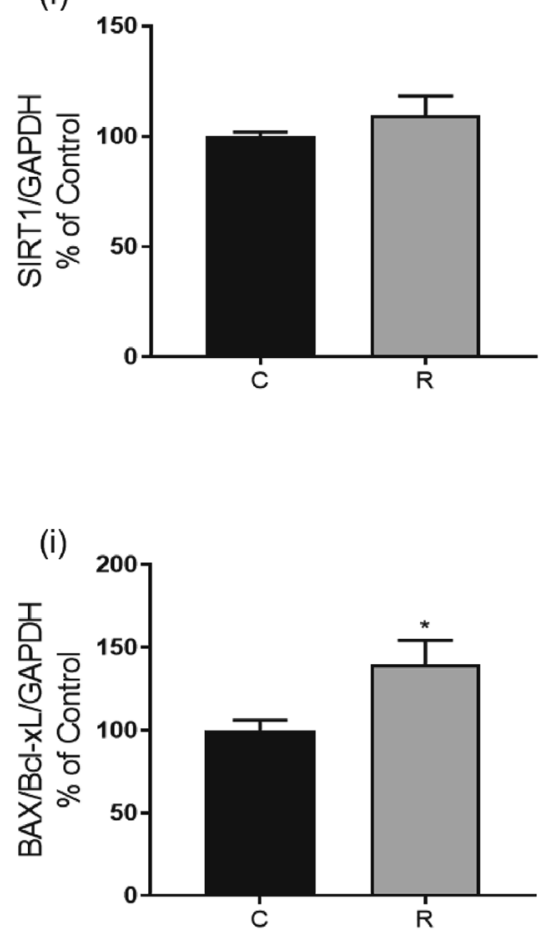

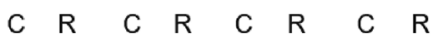

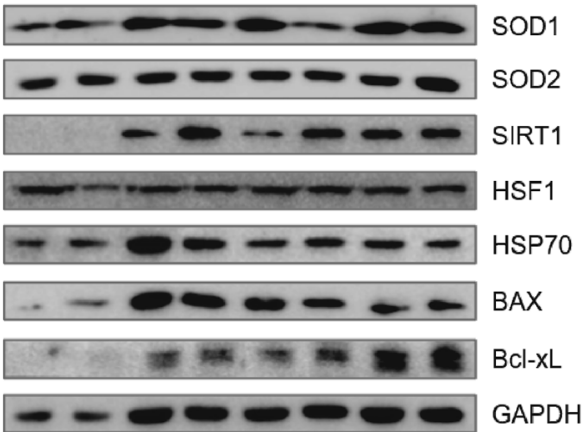

Fig. 3 Analysis of redox balance status and apoptosis pathway. a $\mathrm{H}_{2} \mathrm{O}_{2}$ production by Amplex probe $(n=7)$. b Superoxide content by DHE probe $(n=9)$. c Mitochondrial superoxide content by Mitosox probe $(n=9)$. d-i Protein content of SOD1, SOD2, SIRT1, HSF1, HSP70, Bax and Bcl-xL $(n=5-7)$. j Percentage of apoptotic cells costained with Hoechst 33342 and propidium iodide was pictured and determined by the High Content Imaging System in ImageXpress Micro Confocal $(n=5)$. d-i Normalized by GAPDH and expressed in $\%$ of Control. $* R$ is different from $C$. Data are mean \pm SEM and were submitted to Student $\mathrm{t}$ test for all analyses, except for Amplex analyses, which was analyzed by the Mann-Whitney $U$ test, $p<0.05$ 


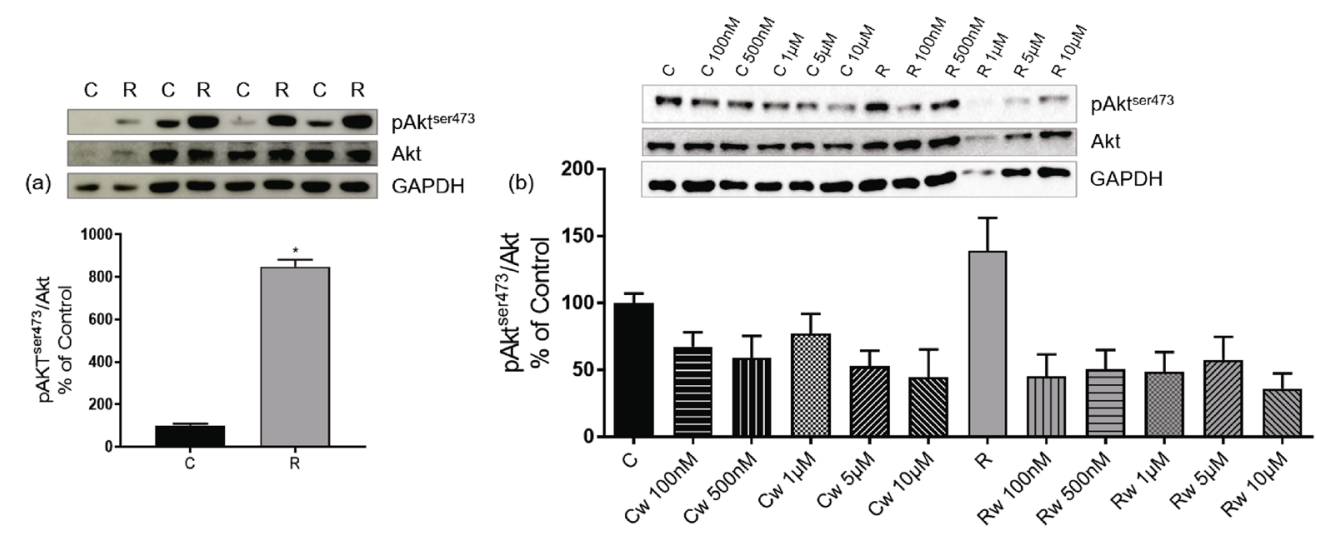

(c)

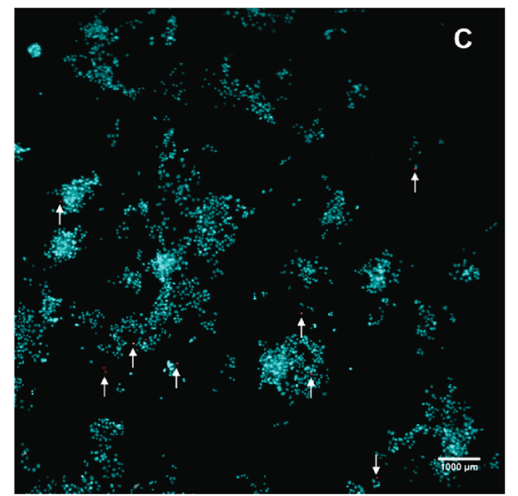

(e)

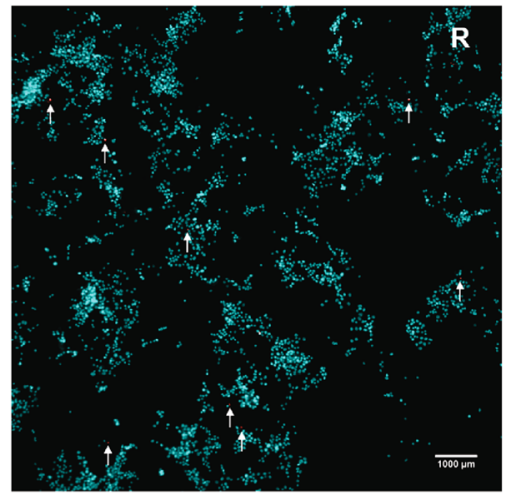

(d)

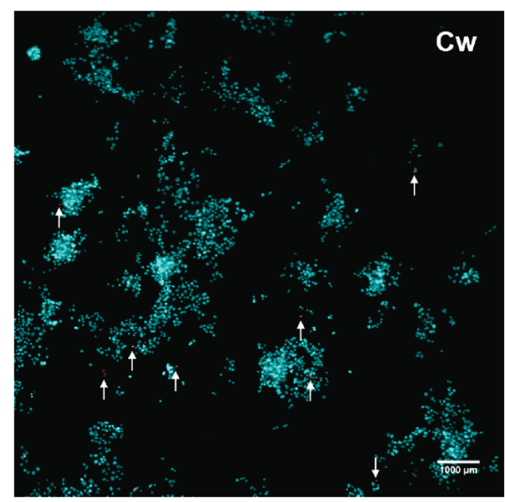

(f)

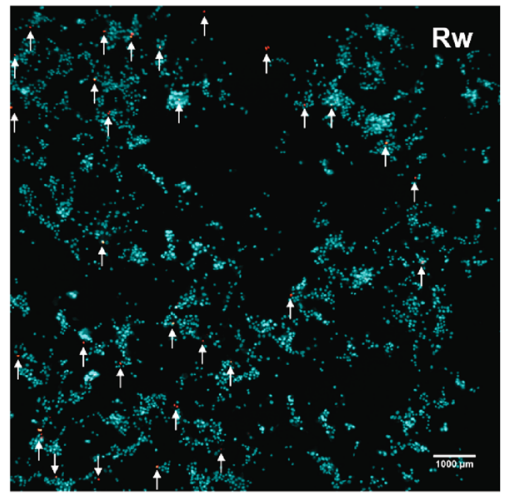

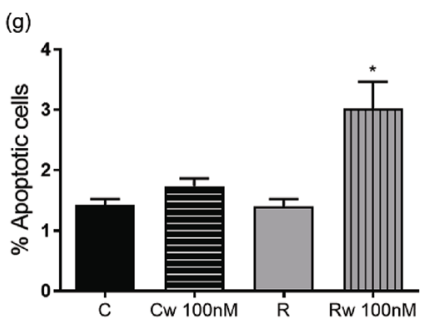
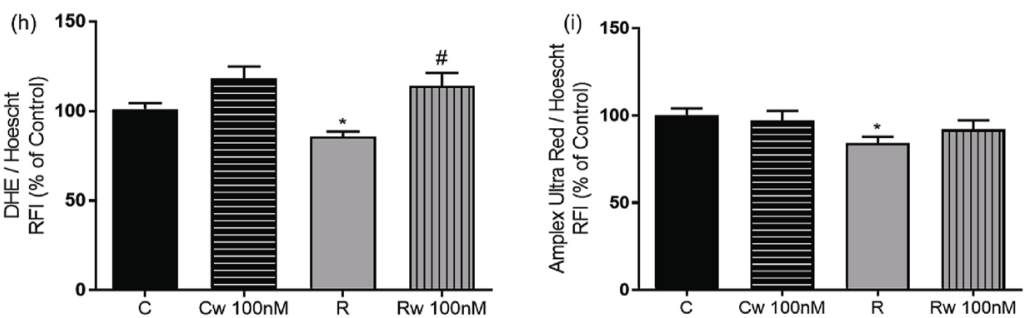

Fig. 4 Evaluation of Akt/PI3K pathway in cell viability and redox balance. Cells were submitted to the treatment with Wortmannin during $30 \mathrm{~min}$ before the $48 \mathrm{~h}$ of amino acid restriction. a Protein content of pAkt/Akt in basal situation and $\mathbf{b}$ after its inhibition by different concentrations of Wortmannin $(n=4-6)$. $\mathbf{c}-\mathbf{f}$ Representative images and percentage of apoptotic cells (g) costained with Hoechst 33,342 and propidium iodide, pictured and determined by the High Content
Imaging System in ImageXpress Micro Confocal $(n=5)$. $\mathbf{h}$ Superoxide content by DHE probe $(n=7)$. $\mathbf{i ~ H}_{2} \mathrm{O}_{2}$ production by Amplex probe $(n=7) . \mathrm{Cw}$ and $\mathrm{Rw}$ correspond to $\mathrm{C}$ and $\mathrm{R}$ pre-treated with Wortmannin. Data are mean \pm SEM and were submitted to Student $\mathrm{t}$ test for pAkt/Akt analyses, and to two-way ANOVA for Wortmannin analyses. ${ }^{*} p<0.05$ effect of amino acid restriction and $\# p<0.05$ effect of Wortmannin 
that amino acid restriction also induces changes in mitochondrial function and biogenesis, reducing mitochondrial density, oxygen consumption, and mitochondrial membrane potential in INS-1E cells, despite overall lower ROS content. In a previous study, Wistar rats treated with an isocaloric and hypoproteic diet ( $6 \%$ proteins) had a higher content of $\mathrm{H}_{2} \mathrm{O}_{2}$ in the pancreatic islets [17]. On the other hand, we demonstrated a lower production of total ROS, and $\mathrm{H}_{2} \mathrm{O}_{2}$ specifically, while the production of mitochondrial ROS remained unchanged. Cappelli and colleagues (2018) measured $\mathrm{H}_{2} \mathrm{O}_{2}$ in islets, which may not reflect the outcomes found in beta cells alone. The increase in antioxidant enzymes found in our study could explain ROS content reported on the restricted group, indicating that amino acid restriction may have triggered compensatory mechanisms.

Heat shock proteins (HSPs) are a class of chaperones with a fundamental role in maintaining cell survival and viability under stress conditions, preventing denatured proteins from forming cytoplasmic aggregates [29]. Considering malnutrition as a type of stress, we evaluated the expression of Hsp70 after $48 \mathrm{~h}$ of amino acid restriction and observed that its protein content was reduced. It is known that to increase HSPs transcription, HSF1, after deacetylation, must bind the heat shock element (HSE) in the nucleus and SIRT1 is the protein responsible for this process [30]. Analyzing HSF1 and SIRT1 protein content, we observed that our restriction model did not lead to changes in the content of these proteins, despite the reduction in Hsp70 content. However, this reduction could be explained by the loss of HSF1-binding affinity during amino acid restriction, as shown by Hensen and colleagues (2012) [31].

According to the direct relationship between Hsp70 and elements of the apoptotic pathway [29], our next step was to investigate whether this decrease would result in changes in proteins involved with apoptosis. We observed a higher $\mathrm{Bax} / \mathrm{Bcl}-\mathrm{xL}$ ratio, which could indicate that the decrease in Hsp70 would be associated with the increase in Bax by allowing its translocation into the mitochondria and increasing apoptosis. Despite greater activation of the intrinsic pathway of apoptosis, there was no increase in the cell death rate. Then, we hypothesized that another survival pathway activation could counterbalance cell apoptosis.

Our results showed an increase in Akt phosphorylation in the restricted group suggesting that this mechanism could contribute to cell survival. To test this hypothesis, cells were treated with PI3K inhibitor (Wortmannin) and cell death rate and ROS production were evaluated. It was observed that at least part of this protective effect was exerted by Akt activation, since inhibiting PI3K/Akt pathway led to higher rates of cell death in the amino acid restricted group, in addition to an increased content of total ROS. Akt is considered a strong regulator of apoptosis, because it can inhibit pro-apoptotic proteins such as caspase- 9 and Bad. Phosphorylation of
$\mathrm{Bad}$, which is also a component of the $\mathrm{Bcl}-\mathrm{xL} / \mathrm{Bad}$ complex, leads to the dissociation of the complex, inhibiting apoptosis [32]. In addition, Akt is also able to phosphorylate and activate I $\mathrm{KB}$ kinase $\alpha$ that is involved with the activation of nuclear factor kappa $\mathrm{B}$, which regulates transcription of genes related to cell survival [33], and also maintains the phosphorylation of transcription factors of the forkhead box protein $\mathrm{O}$ family, by downregulating TNF-related apoptosisinducing ligand, a pro-apoptotic protein [34].

It is worth noting that although we have not used an in vivo model to confirm all events found in this work, some of the changes characterized in vitro, like reduction in insulin secretion, reduction in insulin gene expression and protein content of SNAP-25 and PKC, have already been seen in previous work in the islets of animals fed a low protein diet $[10,13,21,35]$, as well as some proteins that did not have its content modified, like GCK, PC, and PGC1 $\alpha$ [12]. Therefore, changes outlined in this study are likely to occur in animal models of protein malnutrition. Besides, a well-established in vitro model contributes to the study of molecular mechanisms.

\section{Conclusion}

Insulin-producing cells (INS-1E) subjected to an amino acid restriction exhibited an increase in endoplasmic reticulum stress markers, impaired mitochondrial metabolism, despite reduced content of ROS, and an imbalance in the molecular mechanisms related to cell viability. Despite that, the viability is not altered, possibly, through the greater activation of PI3K/Akt pathway, since its inhibition increased cell death (Fig. 5). In summary, our findings contribute to a better understanding of molecular mechanisms involved with beta cell programming by amino acid restriction, which could be helpful for the development of therapeutic targets for the treatment or prevention of harmful malnutrition outcomes.

Supplementary Information The online version contains supplementary material available at https://doi.org/10.1007/s00394-021-02568-2.

Funding This study was financed in part by the Coordenação de Aperfeiçoamento de Pessoal de Nível Superior-Brazil (CAPES-Finance Code 001) and by Fundação de Amparo à Pesquisa do Estado de São Paulo (FAPESP 2015/12611-0).

Availability of data and materials The data that support the findings of this study are available from the corresponding author upon reasonable request.

\section{Declarations}

Conflict of interest The authors declare that they have no conflict of interest. 


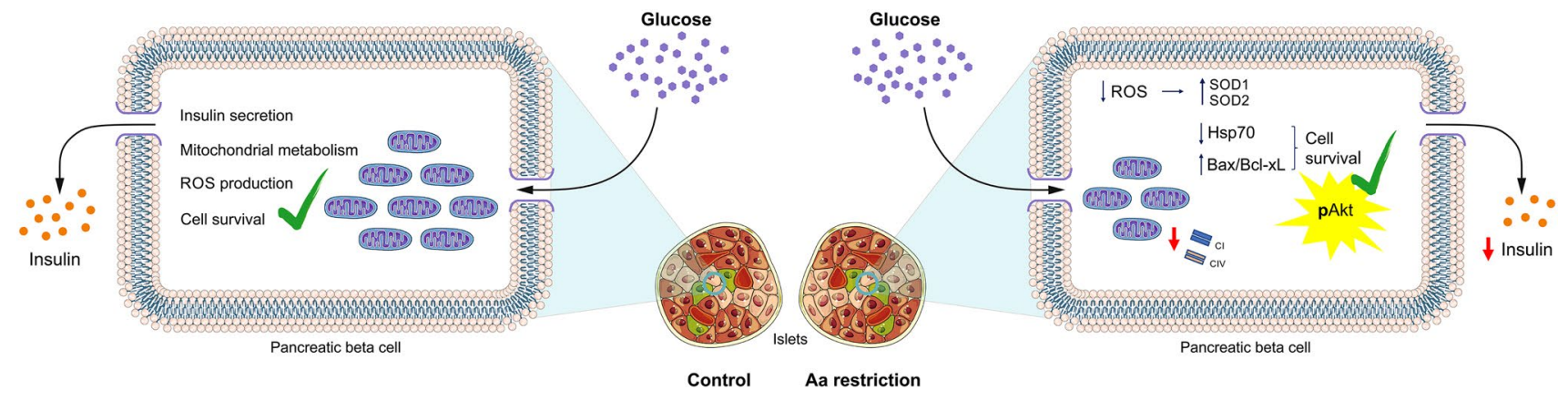

Fig. 5 INS-1E cells subjected to amino acid restriction exhibited reduction in mitochondrial metabolism and increased reticulum stress markers. The amino acid restriction led to an increase in the molecular markers of the intrinsic apoptosis pathway in INS-1E cells.

\section{References}

1. Fact sheets-malnutrition. https://www.who.int/news-room/factsheets/detail/malnutrition. Accessed 12 Mar 2021

2. Black RE, Allen LH, Bhutta ZA et al (2008) Maternal and child undernutrition: global and regional exposures and health consequences. Lancet 371:243-260

3. Sawaya AL (2006) Desnutrição: conseqüências em longoprazo e efeitos da recuperaçãonutricional. EstudAvancados 20:147-158. https://doi.org/10.1590/s0103-40142006000300016

4. Skogen JC, Øverland S (2012) Thefetal origins of adult disease: a narrative review of the epidemiological literature. JRSM Short Rep 3:1-7. https://doi.org/10.1258/shorts.2012.012048

5. Brenseke B, Prater MR, Bahamonde J, Gutierrez JC (2013) Current thoughts on maternal nutrition and fetal programming of the metabolic syndrome. J Pregnancy 2013:368461. https://doi.org/ $10.1155 / 2013 / 368461$

6. Pedraza DF, de Menezes TN (2014) Fatores de risco do déficit de estatura em criançaspré-escolares: estudocaso-controle. Cienc e SaudeColetiva 19:1495-1502. https://doi.org/10.1590/141381232014195.21702013

7. Headey D, Heidkamp R, Osendarp S et al (2020) Impacts of COVID-19 on childhood malnutrition and nutrition-related mortality. Lancet 396:519-521. https://doi.org/10.1016/S01406736(20)31647-0

8. Fore HH, Dongyu Q, Beasley DM, Ghebreyesus TA (2020) Child malnutrition and COVID-19: the time to act is now. Lancet 396:517-518. https://doi.org/10.1016/S0140-6736(20)31648-2

9. Rafacho A, Giozzet VAG, Boschero AC et al (2009) Reduced pancreatic $\beta$-cell mass is associated with decreased FoxO1 and Erk1/2 protein phosphorylation in low-protein malnourished rats. Brazilian J Med Biol Res 42:935-941. https://doi.org/10.1590/ S0100-879X2009001000010

10. Soriano S, Gonzalez A, Marroquí L et al (2010) Reduced insulin secretion in protein malnourished mice is associated with multiple changes in the $\beta$-cell stimulus-secretion coupling. Endocrinology 151:3543-3554. https://doi.org/10.1210/en.2010-0008

11. Leite NC, De Paula F, Borck PC et al (2016) Protein malnutrition potentiates the amplifying pathway of insulin secretion in adult obese mice. Sci Rep 6:1-9. https://doi.org/10.1038/srep33464

12. Branco RCS, Camargo RL, Batista TM et al (2017) Protein malnutrition blunts the increment of taurine transporter expression by a high-fat diet and impairs taurine reestablishment of insulin secretion. FASEB J 31:4078-4087. https://doi.org/10.1096/fj. 201600326RRR
Greater activation of the PI3K/Akt pathway is related to the maintenance of cell viability in INS-1E cells submitted to amino acid restriction
13. Batista TM, Ribeiro RA, Amaral AG et al (2012) Taurine supplementation restores glucose and carbachol-induced insulin secretion in islets from low-protein diet rats: involvement of AchM3R, Synt 1 and SNAP-25 proteins. J Nutr Biochem 23:306-312. https://doi.org/10.1016/j.jnutbio.2010.12.012

14. Da Silva PMR, Batista TM, Ribeiro RA et al (2012) Decreased insulin secretion in islets from protein malnourished rats is associated with impaired glutamate dehydrogenase function: effect of leucine supplementation. Metabolism 61:721-732. https://doi.org/ 10.1016/j.metabol.2011.09.012

15. MateusGonçalves L, Vettorazzi JF, Vanzela EC et al (2019) Amino acid restriction increases $\beta$-cell death under challenging conditions. J Cell Physiol 234:16679-16684. https://doi.org/10. $1002 / j \mathrm{jp} .28389$

16. Theys N, Bouckenooghe T, Ahn MT et al (2009) Maternal lowprotein diet alters pancreatic islet mitochondrial function in a sexspecific manner in the adult rat. Am J Physiol-RegulIntegr Comp Physiol 297:1516-1525. https://doi.org/10.1152/ajpregu.00280. 2009

17. Cappelli APG, Zoppi CC, Silveira LR et al (2018) Reduced glucose-induced insulin secretion in low-protein-fed rats is associated with altered pancreatic islets redox status. J Cell Physiol 233:486-496. https://doi.org/10.1002/jcp.25908

18. Scott AM, Atwater I, Rojas E (1981) A method for the simultaneous measurement of insulin release and B cell membrane potential in single mouse islets of langerhans. Diabetologia 21:470-475. https://doi.org/10.1007/BF00257788

19. Bradford MM (1976) A rapid and sensitive method for the quantitation of microgram quantities of protein utilizing the principle of protein-dye binding. Anal Biochem 72:248-254. https://doi. org/10.1016/0003-2697(76)90527-3

20. Livak KJ, Schmittgen TD (2001) Analysis of relative gene expression data using real-time quantitative PCR and the 2- $\Delta \Delta \mathrm{CT}$ method. Methods 25:402-408. https://doi.org/10.1006/meth.2001. 1262

21. Ferreira F, Filiputti E, Arantes VC et al (2003) Decreased cholinergic stimulation of insulin secretion by islets from rats fed a low protein diet is associated with reduced protein kinase $\mathrm{C} \alpha$ expression. J Nutr 133:695-699. https://doi.org/10.1093/jn/133.3.695

22. Cnop M, Toivonen S, Igoillo-Esteve M, Salpea P (2017) Endoplasmic reticulum stress and eIF $2 \alpha$ phosphorylation: the Achilles heel of pancreatic $\beta$ cells. MolMetab 6:1024-1039. https://doi. org/10.1016/j.molmet.2017.06.001

23. Kuwabara K, Matsumoto M, Ikeda J et al (1996) Purification and characterization of a novel stress protein, the $150 \mathrm{kDa}$ oxygenregulated protein (ORP150), from cultured rat astrocytes and its 
expression in ischemic mouse brain. J Biol Chem 271:5025-5032. https://doi.org/10.1074/jbc.271.9.5025

24. Kusaczuk M, Cechowska-Pasko M (2013) Molecular chaperone ORP150 in ER stress-related diseases. Curr Pharm Des 19:28072818. https://doi.org/10.2174/1381612811319150016

25. Bando Y, Tsukamoto Y, Katayama T et al (2004) ORP150/ HSP12A protects renal tubular epithelium from ischemia-induced cell death. FASEB J 18:1401-1403. https://doi.org/10.1096/fj.031161fje

26. Aleshin AN, Sawa Y, Kitagawa-Sakakida S et al (2005) $150 \mathrm{kDa}$ oxygen-regulated protein attenuates myocardial ischemia-reperfusion injury in rat heart. J Mol Cell Cardiol 38:517-525. https:// doi.org/10.1016/j.yjmcc.2005.01.001

27. Gao YY, Liu BQ, Du ZX et al (2010) Implication of oxygen-regulated protein 150 (ORP150) in apoptosis induced by proteasome inhibitors in human thyroid cancer cells. J ClinEndocrinolMetab 95:319-326. https://doi.org/10.1210/jc.2010-1043

28. Wu YB, Li HQ, Ren MS et al (2013) CHOP/ORP150 ratio in endoplasmic reticulum stress: a new mechanism for diabetic peripheral neuropathy. Cell Physiol Biochem 32:367-379. https:// doi.org/10.1159/000354444

29. Castro SV, Lobo CH, De Figueiredo JR, Rodrigues APR (2013) Proteínas de choquetérmicohsp 70: estrutura e atuação em respostaaoestressecelular. Acta Vet Bras 7:261-271
30. Purwana I, Liu JJ, Portha B, Buteau J (2017) HSF1 acetylation decreases its transcriptional activity and enhances glucolipotoxicity-induced apoptosis in rat and human beta cells. Diabetologia 60:1432-1441. https://doi.org/10.1007/s00125-017-4310-7

31. Hensen SMM, Heldens L, Van Enckevort CMW et al (2012) Heat shock factor 1 is inactivated by amino acid deprivation. Cell Stress Chaperones 17:743-755

32. Datta SR, Dudek H, Xu T et al (1997) Akt phosphorylation of BAD couples survival signals to the cell-intrinsic death machinery. Cell 91:231-241. https://doi.org/10.1016/S0092-8674(00) 80405-5

33. Dan HC, Cooper MJ, Cogswell PC et al (2008) Akt-dependent regulation of NF- $\mathrm{KB}$ is controlled by $\mathrm{mTOR}$ and Raptor in association with IKK. Genes Dev 22:1490-1500. https://doi.org/10. 1101/gad.1662308

34. Zhang X, Tang N, Hadden TJ, Rishi AK (2011) Akt, FoxO and regulation of apoptosis. Biochim Biophys Acta-Mol Cell Res 1813:1978-1986. https://doi.org/10.1016/j.bbamcr.2011.03.010

35. Vettorazzi JF, Ribeiro RA, Santos-Silva JC et al (2014) Taurine supplementation increases KATP channel protein content, improving $\mathrm{Ca} 2+$ handling and insulin secretion in islets from malnourished mice fed on a high-fat diet. Amino Acids 46:2123-2136. https://doi.org/10.1007/s00726-014-1763-6 